\title{
Exigências líquidas de proteína e energia para ganho de peso de novilhos Nelore alimentados com dietas contendo grão de milho úmido e gordura protegida ${ }^{1}$
}

\author{
Soraia Marques Putrino², Paulo Roberto Leme ${ }^{3}$, Saulo da Luz e Silva², Guilherme Fernando \\ Alleoni ${ }^{4}$, Dante Pazzanese Duarte Lanna ${ }^{5}$, Carlos Grossklaus ${ }^{6}$ \\ 1 Parte da tese de doutorado da primeira autora, aluna da Faculdade de Zootecnia e Engenharia de Alimentos da Universidade de São Paulo \\ (FZEA/USP). Projeto financiado pela FAPESP. \\ 2 Pós-graduação - FZEA/USP, Caixa Postal 23, Pirassununga, SP, Brasil - CEP: 13635-900. E-mail: somarqputrino@uol.com.br \\ ${ }^{3}$ FZEA/USP, Pirassununga, SP, Brasil. \\ ${ }^{4}$ Instituto de Zootecnia, Nova Odessa, SP, Brasil. \\ ${ }^{5}$ ESALQ/USP, Piracicaba, SP, Brasil. \\ ${ }^{6}$ Socil Evialis.
}

RESUMO - Neste trabalho, as exigências líquidas de energia e proteína líquidas para ganho de peso foram estimadas pela técnica de abate comparativo utilizando-se 56 novilhos Nelore com peso médio inicial de $432 \mathrm{~kg}$. A análise da composição da $9^{\mathrm{a}}-10^{\mathrm{a}}-11^{\mathrm{a}}$ costelas foi utilizada para estimativa da composição do corpo vazio. Oito novilhos foram abatidos no início do período experimental, para o cálculo da composição corporal inicial, e os demais, alimentados durante 70 dias com dietas contendo $60 \%$ de concentrado na MS, composto de grão de milho seco ou úmido, com ou sem gordura protegida da biohidrogenação ruminal. O peso médio dos animais ao abate foi $528 \mathrm{~kg}$. Apenas o ganho de peso de carcaça quente foi maior nos tratamentos com gordura Não houve diferença na composição do corpo vazio, nas taxas de deposição e na composição do ganho de peso vazio. As exigências de energia e proteína foram de 2,97 Mcal e $0,171 \mathrm{~kg}$ por $\mathrm{kg}$ de ganho de peso corporal vazio (GPVz), respectivamente, e o ganho de gordura foi de $0,215 \mathrm{~kg}$ por kg de GPVz. A utilização do grão de milho úmido e de $4 \%$ de gordura protegida na alimentação de novilhos Nelore não alterou a composição corporal e as exigências de energia e proteína.

Palavras-chave: bovinos de corte, composição corporal, confinamento, ganho de peso, nutrição animal

\section{Net requirements of energy and protein for weight gain of Nellore steers fed diets containing high moisture corn grain and ruminal protected fat}

\begin{abstract}
In this study the net requirements of energy and protein for weight gain were estimated through the comparative slaughter technique using 56 Nellore steers averaging $432 \mathrm{~kg}$ of initial body weight. The analytical composition of the $9^{\text {th }}-10^{\text {th }}-11^{\text {th }}$ ribs was used to estimate empty body $(\mathrm{EB})$ composition. Eight steers were slaughtered at the beginning of the trial to determine the initial body composition while the remaining steers were fed for 70 days diets containing $60 \%$ of concentrate (dry matter basis) composed by dry or high moisture corn grain with or without addition of ruminal protected fat. The average shrunk body weight at slaughter was $528 \mathrm{~kg}$. Only hot carcass weight gain increased significantly by feeding ruminal protected fat to steers. No significant differences were observed for empty body composition, deposition rates and empty body gain composition among diets. Energy and protein requirements were 2.97 Mcal and $0.171 \mathrm{~kg}$ per $\mathrm{kg}$ of empty weight gain (EWG), respectively, while fat gain averaged $0.220 \mathrm{~kg}$ per $\mathrm{kg}$ of EWG. It can be suggested the use of high moisture corn and $4 \%$ of ruminal protected fat on diets for Nellore steers because no significant changes were found in body composition or net requirements of energy and protein.
\end{abstract}

Key Words: beef cattle, body composition, feedlot, weight gain, animal nutrition

\section{Introdução}

A estimativa das exigências de energia e proteína para ganho de peso de bovinos de corte, obtida a partir da composição corporal dos animais, é uma importante ferramenta para a nutrição. Entretanto, a maior parte dos valores de requerimentos destinados à formulação de rações é calculada com base nas necessidades de animais de raças taurinas. Por isso, é importante o estudo da composição corporal dos bovinos criados em condições brasileiras, incluindo os da raça Nelore, que compõem grande parte do rebanho brasileiro.

As diferenças nas exigências de energia e proteína para ganho são atribuídas às variações na composição do ganho de peso (Garret et al., 1959; Geay, 1984), que, segundo Barber et al. (1981), afetam diretamente a eficiência de utilização de alimentos para ganho de peso vivo e para produção de carne comestível. As concentrações de proteína, cinzas e água decrescem com a idade e a engorda, obser- 
vando-se que a maturidade é caracterizada pelo aumento na proporção de gordura (Ferreira et al., 1998).

O nível do consumo de energia pode modificar a partição no uso da energia para síntese de proteína ou lipídios ou, em termos de tecidos, no desenvolvimento de músculo e tecido adiposo. A eficiência de utilização de energia metabolizável para produção é influenciada principalmente pelas características da dieta, como o valor comparativo entre volumoso e concentrado, o teor de fibra, o tempo de ingestão e ruminação e as relações de ácidos graxos voláteis no rúmen (Van Soest, 1994). Jones et al. (1985) observaram que animais alimentados com dietas à base de concentrado apresentaram maiores teores de gordura na carcaça que aqueles cujas dietas eram à base de volumoso.

A exigência de proteína para ganho de peso varia com a raça, o sexo e a taxa de ganho de peso, sendo maior nos animais inteiros que nos castrados e, para mesmo sexo, maior para animais de maturidade tardia que para os precoces (Geay, 1984).

Para aumentar a densidade energética da dieta de bovinos, as opções comercialmente viáveis seriam o processamento do grão para elevar o teor de energia digestível e a adição de gordura.

O amido, principal componente de muitos grãos, representa de 70 a $80 \%$ da composição de cereais e está presente nas raízes e nos tubérculos de leguminosas (Zeoula et al., 1999). É um nutriente primário nas dietas dos ruminantes (Theurer, 1986), nas quais são utilizados grãos como os de cevada, milho e sorgo.

O local de maior digestão do amido nos ruminantes é o rúmen (Theurer, 1986). No intestino, ocorre digestão de $65 \%$ do amido, que é utilizado com eficiência $42 \%$ maior para ganho de peso que quando digerido no rúmen (Owens et al., 1986). Ørskov (1986) afirma que cerca de $30 \%$ do amido do milho escapa da fermentação ruminal, mas a capacidade de digestão pós-ruminal é limitada e dificilmente poderia ser aumentada. O processamento do grão aumenta a degradabilidade ruminal do amido, melhorando o aproveitamento do nutriente pelo animal, como citou Huntington (1997): quanto à produção total de energia metabolizável, o amido é bem mais utilizado quando fermentado no rúmen.

Stock et al. (1987) verificaram que a combinação de milho com alto teor de umidade, que possui rápida fermentação ruminal, com milho seco na dieta de bovinos proporcionou ganho e eficiência alimentar maiores que o uso somente de grão úmido ou seco. Owens et al. (1997) relataram que há maior ganho diário quando o milho grão apresenta entre 30 e $31 \%$ de umidade, provavelmente em razão da maior digestibilidade com o aumento da umidade.
As respostas ao teor de gordura na dieta de ruminantes são variáveis (Haaland et al., 1981).

Johnson \& McLure (1973) afirmaram que o uso de gordura na alimentação de ruminantes pode causar problemas de palatabilidade e reduzir a digestibilidade da fibra, em decorrência do efeito tóxico dos ácidos graxos de cadeia longa sobre as bactérias ruminais (Henderson, 1973). A utilização de cálcio juntamente com a gordura na dieta minimiza os efeitos negativos sobre a digestão da fibra em dietas ricas em forragem ( $>40 \%$ forragem) (Palmquist \& Conrad, 1980).

A combinação de sais de cálcio e ácidos graxos de cadeia longa (cálcio saponificado) tem sido muito utilizada como fonte de energia em dietas para vacas em lactação. Este composto se mantém relativamente inerte no rúmen em condições normais de $\mathrm{pH}$, mas se dissocia completamente nas condições ácidas do abomaso (Jenkins \& Palmquist, 1984), aumentando a densidade energética da dieta sem afetar a utilização da forragem.

Brandt \& Anderson (1995) verificaram que a suplementação de animais em fase de terminação com dietas com gordura aumentou o ganho diário e melhorou a eficiência alimentar.Zinn \& Shen, (1996) também registraram melhoria na eficiência alimentar, como resultado dos maiores teores de energia metabolizável nos lipídios em relação aos carboidratos e proteína.

Nigdi et al. (1990) forneceram dietas com $85 \%$ de concentrado contendo $0,2,4$ e $6 \%$ de cálcio saponificado e observaram que o aumento na concentração do composto de cálcio na dieta diminuiu a ingestão de matéria seca, o ganho médio diário e o peso da carcaça quente, mas não afetou outras características de carcaça.

O objetivo neste trabalho foi avaliar as exigências de proteína e energia para o ganho de peso de animais da raça Nelore alimentados com dietas com $60 \%$ de concentrado contendo grão de milho úmido e gordura protegida da biohidrogenação ruminal, utilizando-se a técnica de abate comparativo, para estimativa da composição química do corpo vazio a partir do corte da $9^{\mathrm{a}}-10^{\mathrm{a}}-11^{\mathrm{a}}$ costelas.

\section{Material e Métodos}

O experimento foi realizado na Faculdade de Zootecnia e Engenharia de Alimentos da Universidade de São Paulo (FZEA/USP), em Pirassununga, SP.

Foram utilizados 56 bovinos machos castrados da raça Nelore, com idade e peso médios iniciais de 36 meses e 432 $\mathrm{kg}$, respectivamente, mantidos em pastagem antes do experimento e apresentando espessura de gordura média inicial de $2,5 \mathrm{~mm}$, mensurada via ultra-sonografia. 
Oito animais, escolhidos por sorteio, foram abatidos no início do período de alimentação, para se estimar a composição corporal inicial do lote (linha base). Os demais foram confinados em quatro piquetes (12 animais por baias) durante 70 dias, após adaptação de 28 dias. O controle da alimentação foi feito individualmente, por meio de portões eletrônicos do tipo Calan. A adaptação foi iniciada após 15 dias de permanência nos piquetes, a fim de habituar os animais aos lotes e ao sistema de alimentação.

As rações experimentais (Tabela 1) foram compostas de $60 \%$ de concentrado na matéria seca e, como volumoso, foi utilizada a silagem de milho, com partículas de aproximadamente $2 \mathrm{~cm}$ e $35 \%$ de grãos. Os concentrados utilizados possuíam grão de milho seco sem gordura (SSG) ou grão de milho úmido sem gordura (USG), milho seco com gordura (SCG) ou milho úmido com gordura (UCG). O milho grão foi triturado na forma de quirera em moinho com peneira grossa (8 mm de diâmetro). A gordura utilizada foi o Lacto Plus ${ }^{\circledR}$, uma gordura protegida da biohidrogenação ruminal, que consiste em um sal cálcico de ácido graxo produzido a partir de gordura vegetal à base de soja ou palma.

As dietas foram formuladas utilizando-se o programa $\mathrm{RLM}^{\circledR}$ (ESALQ/USP), com substituição de parte do milho (seco ou úmido) por $4 \%$ gordura protegida da biohidrogenação ruminal. $\mathrm{O}$ alimento, fornecido à vontade, e as sobras foram pesados diariamente. As pesagens dos animais foram realizadas em intervalos de 28 dias, após jejum completo de 18 horas.

No início do experimento, foi estabelecido que o abate seria feito quando os animais atingissem $6,0 \mathrm{~mm}$ de espessura de gordura subcutânea entre a 12를 13 _
Quando a maioria atingiu esse valor, estimado por ultrasom, os animais foram abatidos dois dias após a última pesagem, após jejum alimentar, no Matadouro-Escola da Prefeitura do Campus Administrativo da USP, Pirassununga/SP, com intervalo de uma semana entre os dois lotes (dois piquetes de cada vez).

No dia do abate foram pesadas as gorduras renal, pélvica e inguinal, o fígado e a carcaça quente. As meiacarcaças foram mantidas em câmara fria por 24 horas à temperatura de 0 a $2{ }^{\circ} \mathrm{C}$. Em seguida, retirou-se o corte da $9^{\mathrm{a}}-10^{\mathrm{a}}-11^{\mathrm{a}}$ costelas da meia-carcaça esquerda, de acordo com a metodologia proposta por Hankins \& Howe (1946). A espessura de gordura subcutânea foi determinada com grade graduada na área seccionada entre a $11^{\mathrm{a}}$ e $12^{\underline{a}}$ costelas.

As amostras dos cortes da costela foram congeladas, cortadas com serra elétrica de fita e processadas em moedor de grande porte (Herman P - 33a - 3 - 789, 15 HP). Em seguida, foram liofilizadas até peso constante, obtendo-se o teor de água do corte da costela.

Para o cálculo do peso corporal vazio (PCVz), foi utilizada a equação de Leme et al. (1994):

$\mathrm{PCVz}=-16,15438+(0,94245 \mathrm{x}$ peso vivo em jejum $)$; $\mathrm{R}^{2}=0,99 ;$ Sy.x $=4,99$

A partir do teor de água do corte da 9 a $10^{\mathrm{a}} 11^{\mathrm{a}}$ costelas, foram estimadas as porcentagens de água e extrato etéreo (EE) no corpo vazio (CVz) utilizando-se equações de Lanna (1988):

$\%$ água $C V z=24,1936+\left(0,6574 X \%\right.$ água corte $99^{\mathrm{a}} 10^{\mathrm{a}} 11^{\mathrm{a}}$ costelas $)\left(\mathrm{R}^{2}=0,911 ; \mathrm{Sy} . \mathrm{X}=0,82\right)$

$\% \mathrm{EE} \mathrm{CVz}=60,815-\left(0,7968 \mathrm{X} \%\right.$ água corte 9 a $10^{\mathrm{a}} 11^{\mathrm{a}}$ costelas $)\left(R^{2}=0,911 ;\right.$ Sy. $\left.x=0,82\right)$

Tabela 1 - Ingredientes das rações experimentais (porcentagem da matéria seca)

Table 1 - Ingredient composition of the experimental diets (\% dry matter)

\begin{tabular}{|c|c|c|c|c|}
\hline \multirow[t]{2}{*}{$\begin{array}{l}\text { Ingrediente } \\
\text { Ingredient }\end{array}$} & \multicolumn{4}{|c|}{$\begin{array}{c}\text { Dieta } \\
\text { Diet }\end{array}$} \\
\hline & $\mathrm{SSG}^{1}$ & $\mathrm{USG}^{2}$ & $\mathrm{SCG}^{3}$ & $\mathrm{UCG}^{4}$ \\
\hline Farelo de soja (49\%) (Soybean meal) & 7,633 & 7,633 & 7,633 & 7,633 \\
\hline Milho grão seco (Ccorn grain) & 48,437 & - & 45,037 & - \\
\hline Milho grão úmido (High moisture corn) & - & 48,437 & - & 45,037 \\
\hline Sulfato de amônia (Ammonium sulfate) & 0,060 & 0,060 & 0,060 & 0,060 \\
\hline Cloreto de potássio (Potassium cloride) & 0,400 & 0,400 & 0,400 & 0,400 \\
\hline Mineral (Mineral premix) & 0,400 & 0,400 & 0,400 & 0,400 \\
\hline Calcáreo (Limestone) & 0,600 & 0,600 & - & - \\
\hline Bicarbonato de sódio (Sodium bicarbonate) & 1,500 & 1,500 & 1,500 & 1,500 \\
\hline Rumensin ${ }^{\circledR}$ (Rumensin) & 0,027 & 0,027 & 0,027 & 0,027 \\
\hline
\end{tabular}

${ }^{1}$ Milho seco sem gordura (corn grain without fat - SSG); ${ }^{2}$ Milho úmido sem gordura (High moisture corn without fat - USG); ${ }^{3}$ Milho seco com gordura (corn grain with fat - SCG); ${ }^{4}$ Milho úmido com gordura (High moisture corn with fat - UCG). 
Para estimativa dos teores de proteína e cinzas no corpo vazio, foram utilizadas as relações proteína:água de 0,3009 e cinzas:água de 0,0747 , calculadas para novilhos Nelore por Leme et al. (1994).

As quantidades de energia e proteína no ganho de peso vazio foram calculadas a partir da composição corporal dos animais, estimada no início e final do confinamento. $\mathrm{O}$ cálculo da energia retida foi realizado considerando-se valores de 9,442 kcal/g para o extrato etéreo e 5,493 kcal/g para a proteína (Reid et al., 1968; Garret \& Hinman, 1969, citados pelo ARC, 1980).

O rendimento de ganho (RG) foi calculado pela equação:

$\mathrm{RG}=((($ PCQfinal - PCQinicial) $/($ PVJfinal PVJinicial) $\left.)^{*} 100\right)$, em que PCQ: peso carcaça quente; PVJ: peso vivo em jejum.

O delineamento experimental foi em blocos casualizados (piquetes), com quatro repetições, em arranjo fatorial $2 \times 2$ (com e sem milho grão úmido, com e sem gordura protegida da biohidrogenação ruminal). As análises estatísticas foram feitas pelo procedimento GLM do programa SAS (1999).

\section{Resultados e Discussão}

Não houve efeito de bloco $(\mathrm{P}>0,10)$ sobre nenhum dos parâmetros avaliados. Portanto, não serão descritos os valores de $\mathrm{P}$ e as respectivas médias obtidas para blocos, pois não possuem nenhum interesse do ponto de vista biológico e foram usados apenas para separar uma possível causa de variação nas análises estatísticas.

Não houve interação $(\mathrm{P}>0,31)$ tipo de milho $\times$ adição de gordura protegida para nenhum dos parâmetros avaliados, exceto para espessura de gordura subcutânea. Portanto, serão consideradas as médias dos fatores independentes, de acordo com o tipo de milho e a presença de gordura.

Os pesos dos animais são apresentados na Tabela 2 e os valores de espessura de gordura subcutânea, na Tabela 3 . O ganho de peso em jejum não diferiu entre os tratamentos. Resultados diferentes foram obtidos por Gassman et al. (2001), que observaram menor ganho de peso em novilhos cruzados em terminação ingerindo 5,17\% de ácidos graxos na forma de sais de cálcio.

Embora o ganho de peso vivo não tenha sido influenciado pelos tratamentos, o ganho de peso de carcaça quente foi afetado positivamente pela utilização da gordura $(\mathrm{P}<0,01)$, com tendência $(\mathrm{P}=0,10)$ à redução com a inclusão do milho úmido na dieta.

Na Figura 1 são demonstradas as médias obtidas com o cálculo do rendimento de ganho. Embora não tenha ocorrido diferença significativa com a inclusão de gordura $(\mathrm{P}=0,44)$ e de milho úmido $(\mathrm{P}=0,11)$ na dieta, as médias obtidas refletem os efeitos aditivo da gordura e negativo do milho úmido, que podem ser importantes na análise econômica do sistema de produção.

Tourinhos das raças Brangus e Nelore alimentados com $60 \%$ de concentrado à base de milho seco apresentaram rendimento de ganho de 58,66\% (Putrino et al., 2006).

O ganho de peso vazio não foi influenciado pelos tratamentos. O ganho de $1 \mathrm{~kg}$ de peso vazio correspondeu a, aproximadamente $1,05 \mathrm{~kg}$ de peso vivo em jejum (PVJ), enquanto, no trabalho realizado por Galati et al. (2004), correspondeu a $1,15 \mathrm{~kg}$ para novilhos Nelore de 21 a 31 meses alimentados com $40 \%$ de concentrado. Portanto, dietas com maior quantidade de concentrado podem ser vantajosas em um sistema de produção de bovinos de corte.

Os resultados de desempenho indicam que o fornecimento de energia para animais da raça Nelore pode ser feito pela adição de gordura protegida à dieta em porcentagem semelhante à utilizada neste trabalho.

O fornecimento de gordura protegida aos animais poderia alterar a deposição de gordura interna (ao redor dos órgãos) e, conseqüentemente, a deposição muscular, exigindo uma equação específica de estimativa da porcentagem de gordura no corpo vazio. Analisou-se o peso de gordura interna (renal, pélvica e inguinal) em kg por $100 \mathrm{~kg}$ de PVJ, obtido após o abate dos animais.

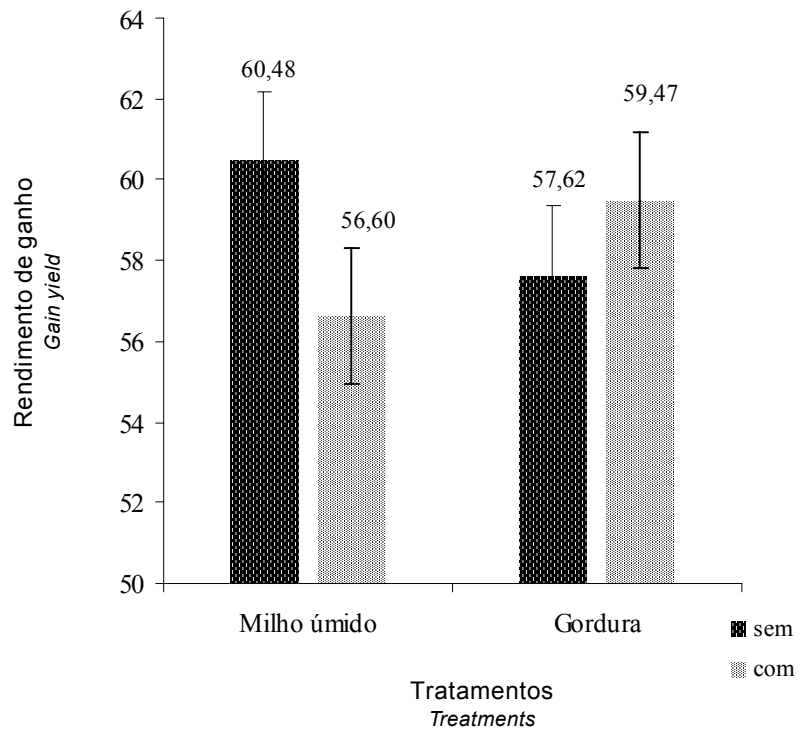

Figura 1 - Rendimento de ganho de novilhos Nelore alimentados com dietas contendo grão de milho seco ou úmido, com ou sem gordura protegida da degradação ruminal.

Figure 1 - Efficiency of gain of Nellore steers fed diets with corn or high moisture corn with or without ruminally degradation protected fat. 
Tabela 2 - Desempenho de novilhos Nelore alimentados com dietas contendo grão de milho seco ou úmido, com ou sem gordura protegida da degradação ruminal

Table 2 - $\quad$ Performance of Nellore steers fed diets with corn or high moisture grain with or without ruminally protected fat

\begin{tabular}{|c|c|c|c|c|c|c|c|c|c|}
\hline \multirow[t]{3}{*}{$\begin{array}{l}\text { Item } \\
\text { Item }\end{array}$} & \multicolumn{6}{|c|}{$\begin{array}{c}\text { Dieta } \\
\text { Diet }\end{array}$} & \multicolumn{3}{|c|}{$\begin{array}{c}\text { Análise estatística (valor de } \mathrm{P} \text { ) } \\
P \text { value }\end{array}$} \\
\hline & \multicolumn{3}{|c|}{$\begin{array}{l}\text { Tipo de milho } \\
\text { Corn type }\end{array}$} & \multicolumn{3}{|c|}{$\begin{array}{l}\text { Gordura } \\
\text { Fat }\end{array}$} & \multirow[t]{2}{*}{$\begin{array}{l}\text { Tipo milho } \\
\text { Corn type }\end{array}$} & \multirow[t]{2}{*}{$\begin{array}{c}\text { Gordura }^{6} \\
\text { Fat }\end{array}$} & \multirow[t]{2}{*}{$\mathrm{MXG}^{7}$} \\
\hline & $\mathrm{MS}^{1}$ & $\mathrm{MU}^{2}$ & $\mathrm{EP}^{3}$ & $\mathrm{SG}^{4}$ & $\mathrm{CG}^{5}$ & $\mathrm{EP}^{3}$ & & & \\
\hline $\begin{array}{l}\text { Peso vivo jejum inicial, } \mathrm{kg} \\
\text { Initial body shrunk weight }\end{array}$ & 439,5 & 423,6 & 5,92 & 433,4 & 429,7 & 5,92 & 0,07 & 0,66 & 0,75 \\
\hline $\begin{array}{l}\text { Peso vivo jejum final, } \mathrm{kg} \\
\text { Final body shrunk weight }\end{array}$ & 533,7 & 521,8 & 8,64 & 525,9 & 529,6 & 8,64 & 0,34 & 0,76 & 0,98 \\
\hline $\begin{array}{l}\text { Ganho peso vivo jejum, kg/dia } \\
\text { Body shrunk weight gain }\end{array}$ & 1,371 & 1,411 & 0,07 & 1,331 & 1,450 & 0,07 & 0,67 & 0,21 & 0,70 \\
\hline $\begin{array}{l}\text { Peso vazio inicial, } \mathrm{kg} \\
\text { Initial empty body weight }\end{array}$ & 396,8 & 382,5 & 5,35 & 391,3 & 387,9 & 5,35 & 0,07 & 0,66 & 0,75 \\
\hline $\begin{array}{l}\text { Peso vazio final, } \mathrm{kg} \\
\text { Final empty body weight }\end{array}$ & 486,8 & 475,7 & 8,14 & 479,5 & 483,0 & 8,14 & 0,34 & 0,76 & 0,98 \\
\hline $\begin{array}{l}\text { Ganho peso vazio, } \mathrm{kg} / \mathrm{dia} \\
\text { Empty body weight gain }\end{array}$ & 1,310 & 1,338 & 0,06 & 1,269 & 1,379 & 0,06 & 0,76 & 0,22 & 0,72 \\
\hline $\begin{array}{l}\text { Peso carcaça quente inicial, } \mathrm{kg} \\
\text { Initial hot carcass weight }\end{array}$ & 241,2 & 232,5 & 3,25 & 237,9 & 235,8 & 3,25 & 0,07 & 0,66 & 0,75 \\
\hline $\begin{array}{l}\text { Peso carcaça quente final, } \mathrm{kg} \\
\text { Final hot carcass weight }\end{array}$ & 300,0 & 287,5 & 4,95 & 290,5 & 297,1 & 4,95 & 0,08 & 0,36 & 0,71 \\
\hline $\begin{array}{l}\text { Ganho peso carcaça quente, } \mathrm{kg} / \mathrm{dia} \\
\text { Hot carcass weight gain }\end{array}$ & 0,863 & 0,790 & 0,03 & 0,756 & 0,897 & 0,03 & 0,12 & $<0,01$ & 0,49 \\
\hline $\begin{array}{l}\text { Ingestão de matéria seca }(\% \mathrm{PV})^{8} \\
\text { Dry matter intake }\end{array}$ & 2,13 & 1,78 & 0,08 & 2,15 & 1,77 & 0,08 & $<0,01$ & $<0,01$ & 0,49 \\
\hline $\begin{array}{l}\text { Eficiência alimentar } \\
\text { Feed efficiency }\end{array}$ & 0,14 & 0,18 & 0,01 & 0,15 & 0,17 & 0,01 & 0,02 & 0,23 & 0,84 \\
\hline
\end{tabular}

${ }^{1}$ Milho seco (corn grain); ${ }^{2}$ Milho úmido (High moisture corn); ${ }^{3}$ Erro-padrão (Standard error); ${ }^{4}$ Sem gordura (Without fat); ${ }^{5}$ Com gordura (With fat); 6 Nível descritivo do teste $\mathrm{F}$ para gordura ( $\mathrm{p}$-value for fat); 7 Nivel descritivo do teste $\mathrm{F}$ para a interação milho $\times$ gordura $(\mathrm{MXG})(p$-value for corn $\times$ fat interaction);

8 Porcentagem do peso vivo (Body weight percentage).

Tabela 3 - Espessura de gordura subcutânea $(\mathrm{mm})$ de novilhos Nelore alimentados com dietas contendo grão de milho seco ou úmido, com ou sem gordura protegida

Table 3 - Backfat thickness $(\mathrm{mm})$ of Nellore steers fed diets with corn or high moisture corn grain with or without ruminally protected fat

\begin{tabular}{|c|c|c|c|c|c|c|c|}
\hline \multicolumn{5}{|c|}{$\begin{array}{c}\text { Dieta } \\
\text { Diet }\end{array}$} & \multicolumn{3}{|c|}{$\begin{array}{c}\text { Análise estatística (valor de P) } \\
P \text { value }\end{array}$} \\
\hline $\mathrm{SSG}^{1}$ & $\mathrm{USG}^{2}$ & $\mathrm{SCG}^{3}$ & $\mathrm{UCG}^{4}$ & $\mathrm{EP}^{5}$ & Milho & Gordura & Interação ${ }^{6}$ \\
\hline
\end{tabular}

${ }^{1}$ Milho seco sem gordura (corn grain without fat); ${ }^{2}$ Milho úmido sem gordura (High moisture corn without fat); ${ }^{3}$ Milho seco com gordura (corn grain with fat); 4 Milho úmido com gordura (High moisture corn with fat); ${ }^{5}$ Erro-padrão (Standard error); ${ }^{6}$ Nível descritivo do teste $\mathrm{F}$ para a interação milho $\times$ gordura (MXG) (p-value for corn $\times$ fat interaction).

Médias seguidas de letras diferentes, na mesma linha, diferem $(P<0,10)$ pelo teste Tukey.

Means followed by different letters, in the same row, differ $(P<0.10)$ by Tukey test.

Não houve efeito significativo $(\mathrm{P}=0,07)$ do tipo de milho sobre o PVJ. Os animais alimentados com milho seco apresentaram $3,12 \mathrm{~kg}$ de gordura por $100 \mathrm{~kg}$ de PVJ e os alimentados com milho úmido, $2,82 \mathrm{~kg} / 100 \mathrm{~kg}$ de PVJ. A inclusão de gordura não alterou $(\mathrm{P}=0,50)$ a quantidade de gordura interna $(2,91 \mathrm{~kg} / 100 \mathrm{~kg}$ de $P V J$ e $3,03 \mathrm{~kg} / 100 \mathrm{~kg}$ de PVJ, para os tratamentos sem e com gordura protegida, respectivamente), não sendo observada interação $(\mathrm{P}=0,67)$ dos fatores milho e gordura. É possível afirmar que a equação para a estimativa da gordura no corpo vazio pode ser a mesma para os animais alimentados ou não com a gordura protegida.
Consta na Tabela 4 a composição do corte da costela e do corpo vazio dos animais.

A porcentagem de água no corte da $9 \underline{a} 10^{\underline{a}} 11^{a}$ costelas e a composição do corpo vazio foram semelhantes entre os animais alimentados com os diferentes tratamentos.

A composição do corpo vazio foi semelhante à observada por Alleoni et al. (1997), em novilhos Nelore de 25,7 meses alimentados com $50 \%$ de concentrado $(57,5 \%$ de água, $21,2 \%$ de extrato etéreo, $17,1 \%$ de proteína e $4,2 \%$ de cinzas). Entretanto, Tedeschi et al. (2002), em estudo com novilhos Nelore de 21 a 24 meses alimentados ad libitum, obtiveram valores mais elevados de gordura 
$(24,7 \%)$, apesar de o peso ao abate ter sido menor (418 kg) que o deste experimento $(528 \mathrm{~kg})$. Os valores dos outros componentes foram de $16,9 \%$ de proteína, $54,6 \%$ de água e $3,87 \%$ de cinzas.

Segundo Murray \& Slezacek (1988), biologicamente, um animal que atinge a maturidade apesenta declínio no peso e na proporção dos órgãos viscerais, especialmente o fígado e o trato digestivo, resultando em uma redução no requerimento de energia para mantença (Ferrel, 1988). Em decorrência do menor requerimento de energia para mantença, proporcionalmente ao peso corporal, mais energia pode ser gasta para o crescimento da carcaça, particularmente a deposição de gordura (Ryan \& Williams, 1989). Portanto, espera-se maior proporção de gordura em animais com maior maturidade.

Putrino (2002) avaliou a composição do corpo vazio em tourinhos Nelore, abatidos com 13 meses e 361,9 kg de PVJ, e registrou $61,22 \%$ de água, $15,05 \%$ de extrato etéreo, $18,84 \%$ de proteína e $4,53 \%$ de cinzas, comprovando que animais mais jovens possuem menor proporção de gordura e maior de proteína que aqueles de maior maturidade.

Nos animais Santa Gertrudis com $322 \mathrm{~kg}$ de peso vazio (Henrique et al., 2003), as porcentagens de nutrientes foram de $59,55 \%$ de água, $16,17 \%$ de extrato etéreo, $20,04 \%$ de proteína e $4,24 \%$ de cinzas. Os valores de extrato etéreo foram menores e os de proteína, maiores que os obtidos nos animais Nelore (491,2 kg de peso vazio), em razão da menor maturidade dos animais da raça Santa Gertrudis.

Na Tabela 5 são descritas as taxas de deposição dos nutrientes e a composição do ganho de peso vazio.

Não houve diferença na taxa de deposição e na composição do ganho de peso vazio entre os tratamentos avaliados.

Resultados diferentes foram reportados por Berndt et al. (2002), que trabalharam com tourinhos Santa Gertrudis alimentados com milho grão úmido ou seco, combinados com silagem de milho ou bagaço de cana-de-açúcar. O milho úmido aumentou o teor de gordura, a taxa de deposição de lipídios e o teor de energia no ganho de peso.

Putrino (2002), em tourinhos Nelore abatidos com $361,9 \mathrm{~kg}$, verificou maiores requerimentos de proteína $(0,188 \mathrm{~kg} / \mathrm{kg}$ de GPVz $)$, menores de energia (2,46 Mcal $/ \mathrm{kg}$ de GPVZ) e menor quantidade de gordura por kg de GPVz $(0,150 \mathrm{~kg})$ que neste trabalho. Esses valores indicam, como proposto por Geay (1984), que as exigências protéicas para ganho de peso são maiores nos animais inteiros que nos castrados.

O NRC (1996) cita a ocorrência de maior porcentagem de gordura e menor de proteína no ganho à medida que o peso corporal aumenta, justificando maior requerimento de energia líquida para ganho. Segundo Grant \& Helferich (1991), isso resulta da desaceleração do crescimento muscular. Resultados semelhantes foram obtidos por Véras et al. (2000) em animais Nelore não-castrados.

Lanna et al. (1997), ao trabalharem com tourinhos Nelore abatidos com $500 \mathrm{~kg}$, encontraram teores de lipídios mais baixos (19\% no corpo vazio) que os registrados neste trabalho $(21,59 \%)$, provavelmente porque o peso ao abate era maior $(527,77 \mathrm{~kg})$ e os animais eram castrados.

\section{Conclusões}

A utilização de $4 \%$ de gordura protegida da biohidrogenação ruminal na dieta aumentou o ganho de peso de carcaça, uma característica economicamente importante no sistema de produção.

O fornecimento de dietas com $60 \%$ de concentrado contendo grão de milho úmido e $4 \%$ de gordura protegida não alterou a composição corporal ou as exigências de

Tabela 4 - Composição do corte da $9^{\mathrm{a}}-10^{\mathrm{a}}-11^{\mathrm{a}}$ costelas e do corpo vazio $(\mathrm{CV} \mathrm{z})$ de novilhos Nelore alimentados com dietas contendo grão de milho seco ou úmido, com ou sem gordura protegida da degradação ruminal

Table 4 - Compositions of the $9^{\text {th }}-10^{\text {th }}-11^{\text {th }}$ rib cut and empty body (EB) of Nellore steers fed diets with corn or high moisture corn with or without ruminally protected fat

\begin{tabular}{|c|c|c|c|c|c|c|c|c|c|}
\hline \multirow[t]{3}{*}{$\begin{array}{l}\text { Item } \\
\text { Item }\end{array}$} & \multicolumn{6}{|c|}{$\begin{array}{l}\text { Dieta } \\
\text { Diet }\end{array}$} & \multicolumn{3}{|c|}{$\begin{array}{c}\text { Análise estatística (valor de } \mathrm{P} \text { ) } \\
P \text { value }\end{array}$} \\
\hline & \multicolumn{3}{|c|}{$\begin{array}{l}\text { Tipo de milho } \\
\text { Corn type }\end{array}$} & \multicolumn{3}{|c|}{$\begin{array}{l}\text { Gordura } \\
\text { Fat }\end{array}$} & \multirow[t]{2}{*}{$\begin{array}{l}\text { Tipo milho } \\
\text { Corn type }\end{array}$} & \multirow[t]{2}{*}{$\begin{array}{c}\text { Gordura } \\
\text { Fat }\end{array}$} & \multirow[t]{2}{*}{$\mathrm{MXG}$} \\
\hline & $\mathrm{MS}^{1}$ & $\mathrm{MU}^{2}$ & $\mathrm{EP}^{3}$ & $\mathrm{SG}^{4}$ & $\mathrm{CG}^{5}$ & $\mathrm{EP}^{3}$ & & & \\
\hline$\%$ água corte $(\% \text { water cut })^{7}$ & 48,7 & 50,1 & 0,53 & 49,5 & 49,3 & 0,53 & 0,07 & 0,86 & 0,33 \\
\hline$\%$ água Cvz (\%water EB) & 56,2 & 57,1 & 0,35 & 56,7 & 56,6 & 0,35 & 0,07 & 0,86 & 0,33 \\
\hline$\%$ extrato etéreo $\mathrm{Cvz}$ (\% ether extract EB) & 22,0 & 20,9 & 0,42 & 21,4 & 21,5 & 0,42 & 0,07 & 0,87 & 0,33 \\
\hline \% proteína Cvz (\% protein $E B$ ) & 16,9 & 17,2 & 0,11 & 17,1 & 17,0 & 0,11 & 0,07 & 0,87 & 0,33 \\
\hline$\%$ cinzas $\mathrm{Cvz}(\%$ ashEB) & 4,2 & 4,3 & 0,03 & 4,2 & 4,2 & 0,03 & 0,07 & 0,88 & 0,33 \\
\hline Energia (Mcal $/ \mathrm{kg})$ (Energy) & 3,01 & 2,92 & 0,03 & 2,96 & 2,97 & 0,03 & 0,07 & 0,86 & 0,31 \\
\hline
\end{tabular}

${ }^{1}$ Milho seco (Dry corn); ${ }^{2}$ Milho úmido (High moisture corn); ${ }^{3}$ Erro-padrão (Standard error); ${ }^{4}$ Sem gordura (Without fat); ${ }^{5}$ Com gordura (With fat); ${ }^{6}$ Nível descritivo do teste $\mathrm{F}$ para a interação milho $\mathrm{x}$ gordura (MXG) ( $p$-value for corn and fat interaction). 
Tabela 5 - Taxa de deposição dos componentes químicos corporais e composição do ganho de peso vazio de novilhos Nelore alimentados com dietas contendo grão de milho seco ou úmido, com ou sem gordura protegida da degradação ruminal

Table 5 - Deposition rates of chemical body components and empty weight gain composition of Nellore steers fed diets with corn or high moisture corn with or without ruminally protected fat

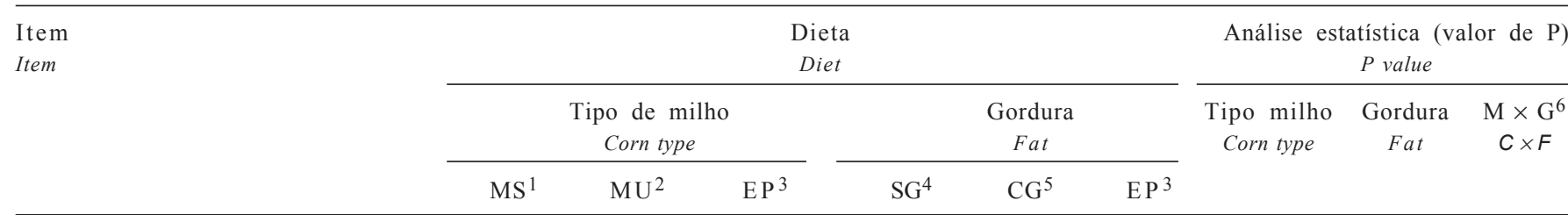

Taxa de deposição

Deposition rate

Água, $\mathrm{kg} / \mathrm{dia}$

Water, $\mathrm{kg} /$ day

Extrato etéreo, $\mathrm{kg} / \mathrm{dia}$

$0,74 \quad 0,76$

0,03

0,72

0,78

0,03

0,56

0,19

0,56

Ether extract, $\mathrm{kg} /$ day

0,29

0,28

0,02

0,27

0,30

0,02

0,68

0,29

0,82

Proteína, kg/dia

$0,22 \quad 0,23$

0,01

0,22

0,24

0,01

0,56

0,19

0,56

Cinzas, kg/dia

Ashes, $\mathrm{kg} / \mathrm{day}$

0,06

0,06

0,002

0,05

0,06

0,002

0,58

0,20

0,56

Energia retida, Mcal/dia

3,95

3,91

0,20

3,77

4,09

0,20

0,89

0,25

1,00

Composição do ganho de peso vazio

Empty weight gain composition

$\%$ Água

$\%$ Water

$\%$ Extrato etéreo

$\%$ Ether extract

$\%$ Proteína

$\%$ Protein

$\%$ Cinzas

$\%$ Ashes

Energia, Mcal/kg GPVz

Energy, Mcal/kg EWG

Proteína, kg/kg GPVz

Protein, Mcal/kg EWG

Gordura, kg/kg GPVz

Fat, Mcal/kg EWG

$\begin{array}{ccccccccc}56,6 & 57,4 & 0,32 & 57,0 & 57,0 & 0,32 & 0,07 & 0,86 & 0,32 \\ 22,2 & 21,0 & 0,44 & 21,5 & 21,6 & 0,44 & 0,07 & 0,86 & 0,32 \\ 17,0 & 17,3 & 0,10 & 17,2 & 17,1 & 0,10 & 0,07 & 0,87 & 0,32 \\ 4,2 & 4,3 & 0,02 & 4,3 & 4,3 & 0,02 & 0,07 & 0,86 & 0,33 \\ 3,01 & 2,92 & 0,03 & 2,96 & 2,97 & 0,03 & 0,07 & 0,87 & 0,33 \\ 0,169 & 0,172 & 0,001 & 0,171 & 0,170 & 0,001 & 0,06 & 0,78 & 0,32 \\ 0,220 & 0,209 & 0,004 & 0,214 & 0,215 & 0,004 & 0,07 & 0,83 & 0,32\end{array}$

${ }^{1}$ Milho seco (Dry corn); ${ }^{2}$ Milho úmido (High moisture corn); ${ }^{3}$ Erro-padrão (Standard error); ${ }^{4}$ Sem gordura (Without fat); ${ }^{5}$ Com gordura (With fat); 6 Nível descritivo do teste $\mathrm{F}$ para a interação milho $\times$ gordura $(\mathrm{M} \times \mathrm{G})(p$-value for corn $\times$ fat interaction $[C \times F])$.

energia e proteína de novilhos Nelore. Pesquisas que estimem as exigências para o ganho de peso destes animais recebendo diferentes níveis de gordura protegida da biohidrogenação ruminal na ração, combinados ou não com grão de milho úmido, possibilitarão a determinação da quantidade ideal destes ingredientes na formulação de rações.

\section{Literatura Citada}

AGRICULTURAL RESEARCH COUNCIL - ARC. The nutrient requirements of ruminants livestock. London: Commonwealth Agricultural Bureaux, 1980. 351p.

AlleOnI, G.F.; LEME, P.R.; BOIN, C. et al. Avaliação da composição química e física dos cortes da costela para estimar a composição química corporal de novilhos Nelore. Revista Brasileira de Zootecnia, v.26, n.2, p.382-390, 1997.

BARBER, K.A.; WILSON, L.L.; ZIEGLER, J.H. et al. Charolais and Angus steers slaughtered at equal percentages of mature cow weight II. Empty body composition, energetic efficiency and comparison of compositionally similar body weights. Journal Animal Science, v. 53, n.4, p.898-906, 1981.
BERNDT, A.; HENRIQUE, W.; LANNA, D.P.D. et al. Milho úmido, bagaço de cana e silagem de milho em dietas de alto teor de concentrado. 2. Composição corporal e taxas de deposição de tecidos. Revista Brasileira de Zootecnia, v.31, n.5, p.2105-2112, 2002. BRANDT JR., R.T.; ANDERSON, S.J. Use of supplemental fat to optimize net energy intake by feedlot cattle. In: Proceedings Intake by Feedlot Cattle, p.303-311, 1995.

FERREIRA, M.A.; VALADARES FILHO, S.C.; COELHO DA SILVA, J.F. et al. Composição corporal e exigências líquidas de proteína e energia para ganho de peso de bovinos F1 Simental x Nelore. Revista Brasileira Zootecnia, v.28, n.2, p.352-360, 1998.

FERREL, C.L. Contribution of visceral organs to animal energy expenditure. Journal of Animal Science, v.66 (Supp1. 3), p.23-34, 1988.

FOX, D.G.; SNIFFEN, C.J.; O'CONNOR, J.D. et al. Search: agriculture. Ithaca: Cornell University Agriculture Experimemtal Station, 1992. n.34, 128p

GALATI, R.L.; EZEQUIEL, J.M.B.; SILVA, O.G.C. et al. Predição da composição química corporal a partir do corte das 9-10-11 ${ }^{\text {a }}$ costelas de novilhos Nelore. In: REUNIÃO DA SOCIEDADE BRASILEIRA DE ZOOTECNIA, 41., 2004, Campo Grande, Anais... Campo Grande: 2004. CD-ROM, Nutrição de Ruminantes.

GARRET, W.N.; MEYER, J.H.; LOFGREEN, J.P. The comparative energy requirements of sheep and cattle for maintenance and gain. Journal of Animal Science, v.18, n.2, p.528-547, 1959. 
GASSMAN, K; PARRISH JR., F.C.; BEITZ, D.C. et al. Effects of feeding calcium salts of conjugated linoleic acid (CLA) to finishing steers. Iowa: Iowa State University, 2001. A.S. Leaflet R1763. p.125-130 (Beef Research Report).

GEAY, Y. Energy and protein utilization in growing cattle. Journal Animal Science, v. 58, n.3, p.766-778, 1984

GRANT, A.L.; HELFERICH, W.G. An overview of growth. In: PEARSON, A.M.; DUTSON, T.R. (Ed). Growth regulation in farm animals. London: Elsevier Applied Science, 1991. p.1-15.

HAALAND, G.L.; MATSUSHIMA, J.K.; JOHNSON, D.E. et al. Effect of replacement of corn by protected tallow in a cattle finishing diet on animal performance and composition. Journal Animal Science, v.52, p.696, 1981.

HANKINS, O.G.; HOWE, P.E. Estimation of the composition of beef carcasses and cuts. Washington, USDA, 1946. (Tech. Bulletin 926).

HENDERSON, C. The effects of fatty acids on pure cultures of rumen bacteria. Journal of Agricultural Science, v.81, p.107, 1973

HENRIQUE, W.; SAMPAIO, A.A.M.; LEME, P.R. et al. Estimativa da composição química coporal de tourinhos Santa Gertrudes a partir da composição química e física das $9^{\mathrm{a}}-10^{\mathrm{a}}-11^{\mathrm{a}}$ costelas. Revista Brasileira de Zootecnia, v.32, n.3, p.709-718, 2003.

HUNTINGTON, G.B. Starch utilization by ruminants: from basics to the bunk. Journal of Animal Science, v.75, p.852-867, 1997.

JENKINS, T.C.; PALMQUIST, D.L. Effect of fatty acids or calcium soaps on rumen and total nutrient digestibility of dairy rations. Journal of Dairy Science, v.67, p.971, 1984

JOHNSON, R.R.; McLURE, K.E. High fat rations for ruminants. II. Effects of fat added to corn plant material prior to ensiling on digestibility and voluntary intake of the silage. Journal of Animal Science, v.36, p.397, 1973.

JONES, S.D.M.; RÓMPALA, R.E.; JEREMIAH, L.E. Growth and composition of the empty body in steers of different maturity types fed concentrate or forage diets. Journal Animal Science, v.60, n.2, p.427-433, 1985.

KREHBIEL, C.R.; McCOY, R.A.; STOCK, R.A. et al. Influence of grain type, tallow level, and tallow feeding system on feedlot cattle performance. Journal Animal Science, v.73, p.29162921, 1995

LANNA, D.P.D.; LEME, P.R.; BOIN, C. et al Ganho compensatório de bovinos de diferentes grupos genéticos: composição química e física corporal. In: REUNIÃO DA SOCIEDADE BRASILEIRA DE ZOOTECNIA, 34., Juiz de Fora. Anais... Juiz de Fora: Sociedade Brasileira de Zootecnia, 1997. p.352-354.

LANNA, D.P.D. Estimativa da composição química do corpo vazio de tourinhos Nelore através da gravidade específica da carcaça e da composição química de cortes das costelas. Piracicaba: Escola Superior de Agricultura Luiz de Queiroz, 1988. 131p. Dissertação (Mestrado em Agronomia) - Escola Superior de Agricultura Luiz de Queiroz, 1988.

LEME, P.R.; BOIN, C.; ALLEONI, G.F. et al. Estimativa da composição química corporal de novilhos Nelore através do espaço de deutério. Revista Sociedade Brasileira Zootecnia, v.23, n.3, 1994.

MURRAY, D.M.; SLEZACEK, O. The effect of weight stasis on the non-carcass components of crossbred sheep. Australian Journal of Agricultural Research, v.39, p.653-658, 1988.

NIGDI, M.E.; LOERCH, S.C.; FLUHARTY, F.L. et al. Effects of calcium soaps of long-chain fatty acids on feedlot performance, carcass characteristics and ruminal metabolism of steers. Journal of Animal Science, v.68, p.2555-2565, 1990.

NATIONAL RESEARCH COUNCIL - NRC. Nutrients requirements of beef cattle. 7.ed. Washington, D.C.: 1996. 242p.
ØRSKOV, E.R. Starch digestion and utilization in ruminants Journal of Animal Science, v.63, p.1624-1633, 1986.

OWENS, F.N.; SECRIST, D.S.; HILL, W.J. et al. The effect of grain source and grain processing on performance of feedlot cattle. Journal of Animal Science, v.75, p.868-879, 1997.

OWENS, F.N.; ZINN, R.A.; KIM, Y.K. Limits to starch digestion in the ruminant small intestine. Journal of Animal Science, v.63, p.1634-1648, 1986.

PALMQUIST, D.L.; CONRAD, H.R. High fat rations for dairy cows. Tallow and hydrolyzed blended fat at two intakes. Journal of Dairy Science, v.63, p.391, 1980.

PUTRINO, S.M. Exigências de proteína e energia líquidas para o ganho de peso de tourinhos das raças Nelore e Brangus alimentados com dietas com diferentes proporções de concentrado. Pirassununga: Universidade de São Paulo, 2002. 75p. Dissertação. (Mestrado em Zootecnia) Universidade de São Paulo, 2002.

PUTRINO, S.M.; LEME, P.R.; SILVA, S.L. et al. Exigências líquidas de proteína e energia para ganho de peso de tourinhos Brangus e Nelore alimentados com dietas contendo diferentes proporções de concentrado. Revista Brasileira de Zootecnia, v.35, n.1, p.312-320, 2006.

RYAN, W.J.; WILLIAMS, I.H. Changes in the body composition of sheep fed a maintenance level. Proceedings Australian Society Animal Production, p.344-347, 1989.

STATISTICAL ANALYSES SYSTEM - SAS. SAS/STAT. User's guide. Version 8. 2. Cary: 1999

STOCK, R.A.; BRINK, D.R.; BRANDT, R.T. et al. Feeding combination of high moisture corn and dry corn to finishing cattle. Journal of Animal Science, v.65, p.282-289, 1987.

TEDESCHI, L.O.; BOIN, C.; FOX, D.G. et al. Energy requirement for maintenance and growth of Nelore bulls and steers fed high-forage diets. Journal of Animal Science, v.80, p.1671-1682, 2002.

THEURER, C.B. Grain processing effects on starch utilization by ruminants. Journal of Animal Science, v.63, p.1649. 1662,1986

Van SOEST, P.J. Nutritional ecology of the ruminants. 2.ed. London: Constock Publishing Associates, 1994. 476p.

VÉRAS, A.S.C.; VALADARES FILHO, S.C.; COELHO da SILVA, J.F. et al. Predição da composição corporal e dos requisitos de energia e proteína para ganho de péso de bovinos, não castrados, alimentados com rações contendo diferentes níveis de concentrado. Revista Brasileira Zootecnia, v.30, n.3. p.1127-1134, (Supl. 1), 2001.

VÉRAS, A.S.C.; VALADARES FILHO, S.C.; COELHO da SILVA, J. F. et al. Composição corporal e requisitos energéticos e protéicos de bovinos Nelore, não-castrados, alimentados com rações contendo diferentes níveis de concentrado. Revista Brasileira Zootecnia, v.29, n.6, p.2379-2389, 2000.

ZEOULA, L.M.; MARTINS, A.S.; PRADO, I.N. et al. Solubilidade e degradabilidade ruminal do amido de diferentes alimentos. Revista Brasileira Zootecnia, v.28, n.5, p.898-905, 1999.

ZINN, R.A.; SHEN, Y. Interaction of dietary calcium and supplemental fat on digestive function and growth performance in feedlot steers. Journal of Animal Science, v.74, p.23032309, 1996. 